\title{
CULTURE AS STUDIED AND CULTURAL STUDIES: AN INTERVIEW WITH GEORGE MARCUS
}

Franklin L. Hess

George E. Marcus, Professor and Chairman of the Department of Anthropology at Rice University, received his Ph.D. in Anthropology from Harvard University in 1976. Through his many publications and through his position as editor of the journal Cultural Anthropology, which he founded in 1985, Professor Marcus has helped shape the "reflexive turn" with which anthropology has been occupied since the 1980s. His ethnographies and reflections on the history and rhetorical construction of ethnography have influenced not only anthropology, but many related fields. His numerous publications include: The Nobility and the Chiefly Tradition in the Modern Kingdom of Tonga (1983), Anthropology as Cultural Critique: An Experimental Moment in the Human Sciences (co-author, 1986), Writing Culture: The Poetics and Politics of Ethnography (co-editor, 1986), Lives in Trust: The Fortunes of Dynastic Families in Late Twentieth Century America (1992), and The Traffic in Culture: Refiguring Art and Anthropology (co-editor, 1995). In March of 1995, as part of the University of Iowa's Distinguished International Lecture Series, Professor Marcus delivered a paper " 'Otherness' in the Prisoner's Dilemma-Paradigm of Cold War Mentalité: An Ambitious Proposal for the Entry of Cultural Studies into Policy Studies." While at the University of Iowa he also participated in activities organized by the Project for the Advanced Study of Art and Life in Africa (PASALA) and presented another lecture, "On Multi-Leveled Ethnography," through the American Studies Forum.

\section{INTRODUCTION AND AUTO-ETHNOGRAPHY}

When people outside of anthropology hear the name George Marcus, probably two books come immediately to mind, Writing Culture: The Poetics and Politics of Ethnography, a collection of essays which you co-edited with James Clifford, and Anthropology as Cultural Critique: An Experimental Moment in the Human Sciences, which you co-authored with Michael M. J. Fischer. Through these two 
books, you're often associated, within the field of anthropology as a whole, with the more experimental, idiomatic as opposed to nomothetic, approaches to ethnographic fieldwork. Is this, in your opinion, a fair characterization?

It is, if I understand the question. One thing that bothered us during the mid1980s was that fieldwork in anthropology_in part because it was still a means to accumulate knowledge for a larger, more dubious project-was not captivating the interest or garnering the commitment of a lot of people who were defining themselves as anthropologists during the 1970s and 1980s. Therefore, there was a basic question of what fieldwork/ethnography, as a paradigm for scholarly work, could and should be. So if you're using the word 'nomothetic' to mean an approach that sees fieldwork or ethnography as a means for building up a kind of archive of difference based upon the models of "man" that anthropology had developed from the 19th century on, then, yes, that was and is a highly questionable project, and, accordingly, the method of ethnography and fieldwork was something that needed to be reworked.

There was, however, a basic commitment to fieldwork/ethnography within the tradition of anthropology in terms of the 1980s critiques. (Clifford's view, as compared to the view of the people who were developing this critique from within anthropology was, however, somewhat different on this point.) Anyway, the thing I wanted to say was that this rethinking of the object of study was the impulse in the 1980s that made our approach to fieldwork/ethnography, under various kinds of critiques, idiomatic, as you say, rather than nomothetic. This was the impulse that made it experimental.

The reason I asked this question is that your approach, because of your reliance on political economy, could actually be said to be quite nomothetic. When you compare yourself to a number of the more experimental writers there actually is more of a law-driven, to paraphrase nomothetic literally from the Greek, impulse in your work than in the work of many of your contemporaries. Perhaps, with this in mind, we could switch to the idiom of "star discourse" and you could situate yourself vis-à-vis other notables such as James Clifford, Stephen Tyler, Renato Rosaldo, Michelle Rosaldo, Vincent Crapanzano, and Marshall Sahlins?

Well, I was always very interested in the problems of how to relate ethnography to the context of world-historical political economy which would seemingly put me far more into the camp of Eric Wolf and Sidney Mintz than it actually does because I don't accept the kind of meta-narrative frames which they use in order to make sense of and define ethnography. So in that way I'm very much concerned with those kinds of "nomothetic" problems, but without the totalities within which they situate their work. And that sets me off from many of these other people that you mentioned, although not so much Marshall Sahlins, because of their concern with the problem of language.

I'm interested in language and the problem of representation, which is the basic critique of the 1980 s, but my inflection upon it is to employ it in terms of the issues of situating the ethnographic subject within political economy and the problems that arise from that. For some of these others, some of them more radi- 
cally than others, the problem of language becomes the whole point of exploration. If you take the critique of representation radically and seriously enough, there is no outside the text, there is no outside the speech act, and therefore a lot of the issues you raise - of political economy, of class, of social theory — go by the wayside. For a lot of the people who most powerfully delivered the critique of representation, it was not an exercise in social theory, but in theories of language.

Now, some of the people who chose this route have tried to work their way back, like Renato [Rosaldo]. But not people like Jim [Clifford] and Steve [Tyler]. A lot of it has to do with different intellectual styles. This is a funny story. Jim at one point was doing these translations of Michel Leiris. We joked that if in the development of this critique we were to divide up the different kinds of ethnographic authority, Steve Tyler, at that moment, and this is an old moment now, would represent charismatic authority ...

This is mid-1980s?

Yes, and Michael [M.J. Fischer] would represent traditional authority and me bureaucratic authority. I'm not sure, however, they would appreciate those characterizations.

What was delightful about that moment was that, although there was a shared set of issues, the intellectual styles of all these people that you mentioned were very, very different. And as an ethnographer, what I've become since then is a kind of pseudo-ethnographer-well, sometimes a serious ethnographer-of this intellectual trend. You see, for me, far more important than the exegesis of the complex systems of thought of this writer or that writer and how these trickled down into the work of others is the question of intellectual styles. I've been fascinated, sociologically and ethnographically, by how this intellectual trend grew into a certain kind of star system, a star track in academia.

I'm interested in hearing a little more about the evolution of your own career within this "star system." You've recently published a book Lives in Trust: The Fortunes of Dynastic Families in Late Twentieth Century America (1992) and a collection of essays which you co-edited, The Traffic in Culture: Refiguring Art and Anthropology (1995). Could you talk a little about the content of these projects and how they relate to your work in Writing Culture and Anthropology as Cultural Critique?

Let me talk about those projects, but deflect them towards two other projects which, because they have not appeared in book form, are not quite as well known. The Dynasties book I began immediately after returning from my original work in Tonga. I was living in Texas and still concerned with lineages of nobility in Tonga and doing this naive thing of being concerned with capitalist lineages, first in Texas, and then much more broadly. I started that work in the late seventies and worked on it throughout the 1980s.

That's a long time. 
Well, this has something to do with how you do fieldwork in your own society. Because it's episodic, you do more intensive periods. It's much longer; it's not cut up into going there and coming back. So, anyway, I worked on that throughout the 1980s, and actually this mid-1980s critique of anthropology intruded upon that project and forced it to become a kind of background vehicle for ethnographically thinking through some of the issues in Anthropology as Cultural Critique and Writing Culture. So you have to see that there's this dual focus to my work. I've always done a lot of things, but not in a scattered way. I mean there have been multiple foci to my work.

So the book which I finally published took on a form which I hadn't necessarily seen at the outset. I had to finally decide. Was I going to write a monograph? What form should it take? I could have written it as Local Dynasties in Galveston, Texas. Then I was going to put together a book called Dynasties in the Transformation of American Culture from the Late 19th Century to the Present, but that never happened. What did happen, however, is part of the ethnography of careers of which I was talking earlier. Over the years, I was invited to this that and the other conference or meeting, and I prepared essays, including various essays about the dynasty stuff that reflected what I was thinking during this long period of research. So I asked myself, "Am I going to actually write this book as a standard kind of ethnography?" And the answer was probably, "No." Most of what I wanted to say was already in these various essays. So I published my essays, some of which had already been published, and I added a few. It's a standard style now. Very few people write books after their initial enterprise in anthropology. They hope to put together a book from their first fieldwork - which is often the most serious work that many anthropologists ever do-then later they do riskier stuff that's a little less systematic. There's simply not the impulse to actually write another ethnographic monograph.

Another thing that's a trademark of my own work is that I love collaborative work. So this book, Lives in Trust, has a long mini-monograph by a very good historian of dynastic families, Peter Dobkin Hall, with whom I have been working since 1980. There's great pleasure in doing work this way.

The other book (The Traffic in Culture), once again, is another aspect of my associations and interests. It's a book I edited with Fred Myers. You see, what happened is that the Lives in Trust project had several spin-offs, one of which was an interest in collecting-great art collections, the meaning of art collections to their collectors, patronage, etc. In the late 1980s, then, I was invited out of the blue to the Getty Center for the History of Art and Humanities, and, once again, I was invited to do the thing I was least likely to do. I was invited, I guess, because of the 1980s critiques, but I was really interested in art collections at that time and this was a tremendous opportunity to study probably the last great private collection that will be institutionalized in a dramatic way. The Getty is one of the last collections in the style of the great robber-barons of the nineteenth century.

So, I actually studied the Getty Trust while I was at the Getty Center. Fred, meanwhile, was someone I had associated with earlier in Oceania work. Anyway, there was a conjunction of a number of things-I was also invited to write an 
essay for a catalogue for an art exhibition which attempted to explore the theme of power in recent American art-and this conjunction has lead to the publication of The Traffic in Culture. This actually is a future area of research for me. I think the whole area of art, aesthetics and institutions, is a great opportunity for exploring a lot of the more experimental moves that have been thought about and suggested during the 1980s.

Two things that have concerned me a lot, aside from these and not reflected in my other books, are the Cultural Studies movement and a series of books which I'm editing called Late Editions. Several years back I was contracted to write a book on the Cultural Studies phenomenon. I've written bits and pieces of it. I've presented the material at various places, and there's been considerable interest in it. But I've resisted for one reason or another actually completing this book, even though it's a very small book.

You see, I did an essay when I was at the Getty on traveling through the hyperreal world of "centers" - of Cultural Studies centers, of humanities' centers, and of various places here and abroad. And that essay, which I published in Cultural Anthropology and which was republished in Re-Reading Cultural Anthropology, stimulated an editor at the University of California Press to ask me to do a short book, one-hundred pages, which wasn't going to be a champion of Cultural Studies or its paradigms and ideas or anything. Instead, it was going to be an ethnographic travel memoir. It was going to deal precisely with Cultural Studies' ethnographic, institutional, and, if you want, sociological contexts, such things as the people who are involved in this interdisciplinary sphere of academia and the context in which it arose and how it arose in the U.S. out of the whole, shall we say, broader trend of the postmodern moment. It was also going to deal with the nitty gritty things that I had observed as a traveler through this space: things like celebrity academics, the double-edgedness of people presenting ideas as public intellectuals but also having academic careers, the fate of the intellectual in the academy, reading habits, the mechanics of reading, things like this. It's still needed, but it would have been much more powerful at the time-this whole domain is on moving ground.

OK, that's one project. The other one began when I finished editing Cultural Anthropology. My university was kind enough to continue the stipend that they paid me to produce it there so that I could consider another kind of publication venture. I came upon the idea of producing a set of annual books lasting until the end of the century at which point it would go out of business. Originally, I was going to call it The Fin-de-Siècle Chronicles knowing at that time-this was about three years ago when we started thinking about it-that "fin-de-siècle" was going to be a very cliched term. The University of Chicago is now doing this series, but they didn't want the Fin-de-Siècle title. Strangely, they thought that if we used a "Frenchism," no one would buy it. So, brainstorming on the phone one day, David Brent (the Chicago editor) and I retitled it Late Editions, Cultural Studies for the End of the Century.

We chose the title Late Editions, on the one hand, to signify a connection with journalism. On the other hand, we hoped the title would indicate that the series 
confronts the crisis of representation that we posed in the mid-1980s. It makes a statement, at times bold, at times more subtle, that discourse on events as they unfold is inadequate - that it fails to establish any kind of authoritative interpretation of them. We thought, particularly from the angle of anthropology, that the most interesting discursive reflection on most events comes from the social actors themselves. The idea, thus, was to invite academics-mostly anthropologists, but also people from literature and other fields as well-to explore areas in which they have expertise. But, we didn't want them to write essays. Instead, we asked them to develop interviews, conversations, or dialogues which could then become the basis of the articles which compose each volume.

Although the interview form has a mixed reception, I've always been impressed with the power of interviews. Good interviews are absorbing. People who' ve never read the ideas of Derrida, Lyotard, or Said have often learned about them most powerfully by reading their interviews which essentially explain ideas through the personal. So my idea was that we'd do a volume a year. There'd be a topical subject, but, unlike the usual academic volume, there wouldn't be an introduction that tries to define a field. Nor would there be a set of coherent papers by experts. Instead, it would be much more speculative. We'd juxtapose interviews from various sources. Also, we would focus neither on "stars" nor ordinary people, as such, but on middle-class types roughly like the interviewers but embedded in very different circumstances.

\section{What kind of process do you go through to produce a volume?}

Well, we have two meetings a year at Rice University. At one meeting we put together the end product, and at the other we start anew with another volume. Each spring I get a couple of consultants from elsewhere, and we brainstorm about what would be an interesting volume. Then over the summer, I recruit, like a managing editor, shall we say, correspondents. I catch people at various phases of work, or recruit someone who did some related work long ago. So they work on their assignments during the year and we meet in May, and have a collective editorial meeting where we go through the pieces in preparation for revision.

One volume has come out. It's called Perilous States: Conversations on Race, Culture, andNation. A second is just about to come out; it's called Techno-Scientific Imaginaries. There's a third one (which is actually going to be a third and fourth one) on media which is called Connected. And the one in development for this year is called Corporate Futures. Generally, I try to get to deal with topics that have not been overly dealt with in the Cultural Studies world. We're not going to deal with fundamentalism or something like that. My feeling is that the series will become known just before it dies because it will take an accumulation of the books for people to take notice. The books actually cross-reference, and there are articles in each that go backward and foreword. So this publication project is a major effort of mine, and it's actually pushed me to go out and do interviews again. For instance, what I had to say yesterday about the double-voiced discourse of the policy world came from interviewing consultants, former academics who are now operating in this sphere. Talking with these people has given 
me tremendous insights into the deployment of culture in, not unsuspected, but ignored spaces.

\section{GENEALOGIES AND SUCCESSIONS: CULTURAL STUDIES IN NORTH AMERICA}

Could we use that as a transition to maybe talk a little about Cultural Studies in North America? I've noticed in a lot of your more theoretical work, for example, your piece in Writing Culture, "Contemporary Problems of Ethnography in the Modern World System," you've borrowed heavily from the British Cultural Studies tradition. I'm thinking, in particular, of your affirmation of Raymond Williams' call for "examples of practice" as a means of resolving the "crisis of form" in realism and your espousal of Paul Willis' study of English working class boys, Learning to Labour, as an example of ethnographic scholarship which takes significant steps toward resolving the representational crisis which Williams identifies. It seems to me, however, that your understanding of the British Cultural Studies tradition is significantly different from the one which dominates the Cultural Studies movement in North America. How does your scholarship converge with contemporary Cultural Studies? Where does it diverge? Where are you trying to fill in the blind-spots to which contemporary Cultural Studies in North America is oblivious?

First of all, my borrowings from the British Cultural Studies' tradition were eclectic and not systematic. In the early '80s, when I was writing these pieces, Cultural Studies had not become as institutionally embraced and delimited as it would become from, say, about 1987 or 1988 and on. There were people, Larry Grossberg and others, who were real aficionados of British Cultural Studies in this country. What Cultural Studies came to represent here, however, was a very loose attempt, under the British example, to institutionalize previous intellectual trends. Postmodernism has become a kind of used-up word that people can't quite get rid of. It still sticks, but it's a word more of suspicion that any thing else. It's a very complex genealogy from postmodernism to Cultural Studies, but it is, nonetheless, a genealogy of succession. Cultural Studies gave institutional form and a leftist political flavor to all the loose discussion about postmodernism while making use of its primary intellectual capital (French though of the 1960s).

So, here I was with this interest in political economy which I thought that the interpretive types in this country had basically ignored. I knew the sociological tradition of ethnography in England, and I thought it was pretty naive. The British Cultural Studies movement was just right: not too cold, not too hot, but just right. Willis' book, but nothing he's done since, was a profound book in terms of ethnography and in terms of some classical issues of social theory. And, of course Williams was the great inspiration for paying attention to substantive political and theoretical issues of form. He was instrumental in the endeavor linking form to political economy, whereas in the American context people were inclined to think form was just form. Basically, however, I would not affiliate myself with British Cultural Studies. Otherwise, I respect it and admire it. So, yes, it's a clear influence, but not systematic. 
Now you have to understand that the Americans who took on the British Cultural Studies paradigm were people who were basically trained in humanistic scholarship, not so much history, but in literary and media studies. Cultural Studies for them was a means to both politicize themselves and to make themselves more empirical. I come from the tradition of anthropology which has been discounted in England as a source for understanding what ethnography is. And the English anthropologists probably deserve to be ignored when it comes to the study of modernity. But I nonetheless come out of this tradition for which a lot of the constructions in Cultural Studies - and in particular its notions of ethnography - are clearly inadequate. Its project was absolutely exciting, but, to be honest, I look at it as historical. I really don't believe that that particular moment (post-War England, especially the 1950s moving into the 1960s) can be reproduced here. Like many, many others - and the numbers have been increasing I have a great ambivalence about Cultural Studies in North America.

So, I've always said that I'm someone who likes to explore the borderlands between this trend, which has much to offer, and anthropology. I would never, however, put myself inside Cultural Studies. I like identifying with anthropology, but I like being on the edges. I've always said that anthropology, primarily cultural and social, is a one paradigm field, and I thought turning to Cultural Studies would open up some legitimate alternatives. But, on the other hand, I've felt some of the anthropologist's resentment-well not really resentment. I don't resent Cultural Studies, but I have a sense that what they're doing is covering considerable ground and making the mistakes that anthropology already has. Right now I think Cultural Studies is stalled, and I think it's stalled in the way I was talking about in my lecture the other day.

\section{It's defining its focus too narrowly in terms of textual hermeneutics?}

Well, what it's doing is fine, but the number of framing narratives it uses has shrunk. For people who are really into it, it still serves a purpose. But in terms of gauging its progress - which as I said is one of my projects - my own position is that it has become seriously stuck in various ways - in terms of its own claimed aspirations: to be political, to be involved, etc. Of course, it can insist that it knows better, but I think it really hasn't played a very interesting political or intellectual game at all. It needs a new challenge for itself or it will become something else. I'm afraid, in the 1990s, with everything becoming so damned conservative, Cultural Studies will become the humanities again.

Did you ever entertain hopes that Cultural Studies would run with the ethnographic ball more than it has? Could ethnography be a means of re-stimulating Cultural Studies or has that moment and that possibility passed us by?

In terms of fashion and trend, that moment has passed, in part, because they already settled on their version of ethnography. They being the Cultural Studies practitioners.

But it doesn't really seem that Cultural Studies, at least in North America, ever really embraced ethnography. 
Something you have to understand about these movements is that people who were trying to be institution builders were bound to fail from the very beginning. Take for example the introduction to that big tome, Cultural Studies. The book contained all this diverse stuff, then at the beginning there was this slight effortand it was a humble effort - to try to define what Cultural Studies was, what it could be, what a paradigm for the endeavor might be. It wasn't strong in that respect, nor could it be. It was bound to be defeated because one of the sociological and ethnographic characteristics of the moment was a willed sense of fundamental interdisciplinarity — not the kind of interdisciplinarity that says let's all get together and mix and share our disciplines, but an interdisciplinarity which said let's get together and deny disciplines for the sake of something higher and better.

That was the French moment, that is, the Barthian moment, in the whole endeavor. It was a conscious decision not to let it have a coherent definition because a lot of people understand that when that happens, it's over. And a lot of people wanted to keep it going. So, there was this willed decision not to let it settle into a definition, but even that kind of process runs out, because there are other forces around you, other intellectual forces and power-knowledges.

\section{Can you elaborate?}

Well, first of all, there's economics. Again, it's what I argued yesterday; cultural Studies discourses have never been able to get along without very strong senses of a political and economic referent, even if only off-stage. They've settled on certain ideas - which, in general, have been very shrewd ones-about what's been happening in the world and why that's totally consistent with the flow of opened-ended discourse and change that is postmodern, now Cultural Studies, discourse. But what the people who are responsible for creating those discourses haven't attended to is concurrent intellectual paradigms, like the people I was mentioning in my presentation. Like Charles Sable.

\section{Charles Sable?}

The guy I was with at the institute who wrote The Second Industrial Divide. These people were open to the introduction of, shall we say, French thinking about culture, but they were operating in an area where they had to talk to policy people. Charles was going to conferences in Austria and worrying about whether Austria was going to go this way or that in new economic regimes. So the economistic paradigm - the old positivist paradigm that we thought we'd done away with - has been a shadow throughout this whole thing. It's been there the whole time. It's been changed, but it's been doing just fine. So, what I'm saying is that the Cultural Studies paradigm is an odd little thing compared to the way...

The way the world does its business?

Yes. Take, for example, my interviews with consultants for corporate futures. There's a lot of very interesting work that's trying to look at corporate discourse and determine the effect of this whole postmodern moment, which has not just 
been an academic moment, upon the discourse of, shall we say, instrumentalists. So, it's important to acknowledge that Cultural Studies has not emerged from an intellectual vacuum. Not for a moment, however, am I suggesting that these parallel discourses have been the same as the discourse that has been developed by Cultural Studies. There is, however, a familial resemblance, and I think that has to be acknowledged and worked through in order to establish what I would call an effective world politics as opposed to an imaginary politics which is what Cultural Studies has.

\section{Is "studying up" a pathway to a more effective politics?}

Yes, but I'm somewhat ambivalent about that term. "Studying up" is Laura Nader's old term from the late 1960s in anthropology and it reflects an assumption that the anthropologist's favored position is subalternity, you know, populism, making common cause with whatever group of people. That's not to say there's not a moral aspect to anthropology. There is, and it's absolutely important. But studying power domains should not be viewed as "studying up" if the term "studying up" is used to suggest that the anthropologist is not implicated in these power domains. They're always already implicated in these power domains.

"Studying up," for instance, is not studying what George Bush thinks. We'll never know what George Bush thinks. Whatever power monger you want to think about - the head of a corporation, the head of a country-you never know what they think, you only suppose. That's not "studying up." "Studying up" is studying - as I was posing this to Virginia [Dominguez] yesterday - what happened to people of our generation who didn't do what we did, but who were successful. It's studying some friend you had in college who now works in the lower levels, but important levels, of the state department. That's "studying up."

I've studied dynasties, and the fieldwork is like Citizen Kane. There's this obsessual, unreachable central object, a person-well-known, but not only wellknown to you-a celebrity. Then there are many circles around him or her, and what's accessible for the ethnographer is generally lots of indirect material about what's at the center of these circles. That's "studying up." That's where the power is. Another example is this whole intellectual enterprise of studying collections, which a graduate student of ours has been doing. It's a fascinating process. There's this central collector, and of course you want to focus on his or her philosophy. But what's happening now is that the collections have been institutionalized. They've become collectivities and, as a result, a dialectic has emerged between the collector and the collection as institutionalized. In "studying up," what's always absent - the holy grail, so to speak —is what's in the mind of the decision maker. What's absolutely available to you is the discursive formations of those who rule. That's as available to you as questioning people in New Guinea about their cosmology. But see, studying up is something that's mystified because the term itself reflects the tremendous ethical, moral, ideological and anxiety load that the anthropologist bears.

Do you have another term that you prefer to "studying up?" 
No, I don't have another term. I prefer a flood of words to a slogan. The Late Editions project, for example, operates on the same turf. It's not about studying famous intellectuals or famous people. Nor is it about studying exotic people. It's about studying, in other situations, people like us, and the idea for the reader is to understand the differences and the similarities. You see, real "studying up" could open up Cultural Studies in a very powerful way. It could unstick it. But it could also create a lot of problems and anxious, foolish debates about selling out.

\section{THE ETHNOGRAPHER, CULTURE, AND THE WORLD}

Why don't we switch gears a little bit here. Now that you've had a chance to situate yourself as both a disciplinary and interdisciplinary student of culture, I'd like to ask you to think a little about the future of ethnography and about the changing character of encounters with the Other. We kind of touched on this when you talked about your work with dynastic families in Texas, Lives in Trust, and the transition you made to doing that from your earlier ethnographic study, The Nobility and Chiefly Tradition in the Modern Kingdom of Tonga (1981). Geographically, politically, and culturally, these two locales could scarcely be more disparate. What factors pushed you to make this transition? How did you convince yourself, in other words, that relocating as a fieldworkerfrom the South Pacific to America was part of a productive intellectual and professional trajectory?

What this gets into, in a very round-about way, is the question of the value of reflexivity in constructing ethnographic work. It seems to me that one of the main currents present in cultural anthropology after the mid-1980s was an attempt to contain the idea of reflexivity, to tame its more radical possibilities. There was an attempt, in other words, to write off of reflexivity as being too self-indulgent, cleaving to the proposition that "we're scientists, we understand that we have biases, but we operate with objectivity and distance from the object of study." I think the real productive implication of the mid-80s critique was that the possibility exists for us to develop ethnographic research, call it objective if you like, which meets certain standards of evaluation based upon reflexive strategies of construction. That to me is a future for ethnography that is worth developing.

Ethnography, then, seems to be becoming more of a discipline of always situating yourself in the world, whether it be in Tonga or Texas.

Oh, absolutely. I think the old naiveté has passed, but I still allow for many styles. I allow for the old kind of ethnography where you arrive, you see, and you talk about everything as distanced. If you were brilliant, it worked; it had its effect. It's a paradigm, and none of these paradigms ever disappear. It may be limited, but it's not inherently flawed. I do think, however, the critique of the ethnographic tropes has fundamentally changed not just the way ethnography is written, but the way the fieldwork is done.

In one version, which is probably the version which actually animated my initial fieldwork in Tonga, I went to study Tonga for reasons that, at that point and 
time, seemed more intellectual than personal. They were personal to the extent that I was interested in my topic, but my project was defined to me by a certain set of disciplinary parameters that prioritized the process of going to different parts of the world and studying ethnological and ethnographic problems. So, when I came back, it seemed logical to continue research which dealt with the phenomena of lineage and nobility, even though, on the surface, Tonga seems very different from Galveston, Texas.

But that's a very distanced, unreflexive way of looking at a problem-interest. A lot of anthropologists did this and continue to do this. The other way to tell the story is to admit that the real reason I pursued the study of dynastic cultures was that I' $m$ very interested in certain issues of family legacy in terms of my own family, which is not a dynastic family. I'm interested in the question of inheritance, not just in terms of material things, but in terms of character, personality, and selfhood. So, the point is that the whole project became a very reflexive process, and, as a result, was enriched. In fact, I would say in general that for younger scholars this kind of reflexive construction of objects of study produces more powerful work.

As for the future of ethnography, most of the possibility that we saw in the mid80 s remains unfulfilled. Whether it will be or.not is an open question. I think the possibility of reshaping ethnography, of transmuting it, of combining it with other methods and experiences of investigation is something, even in this era of more quantifiable work, that has a great future. The question is whether it has a niche. You know, I can't speak about the future of anthropology; that's something that's much more tenuous. But remember, ethnography is not anthropology's possession. It cuts across a lot of things, including Cultural Studies. So the fate of ethnography - whether any of its potential gets realized-depends on the fate of the institutions, the trends, the disciplines, and that is far less sanguine. I tend to be an optimistic person, but it's very bleak.

You see, I care about anthropology, but I care more about the things that actually make interesting scholarship possible. One of the great thing about my department, as compared to many other departments of anthropology, is that we never stop for a moment to ask, "Is this anthropology or not?" We let that question be decided in the evaluation of the project. Sometimes we care about whether a given project is good or bad, or about whether it's going to work or not, but we never have this meta-anxiety about ...

About whether a given project constitutes part of a disciplinary tradition or not?

Yeah, and in most departments that's what kills progress. It's not a tragedy, but I get very frustrated with this type of situation.

I want to push you in the direction of thinking about global homogenization, Americanization, modernization-whatever word you want to attach to the phenomenon. How is cultural anthropology encountering it? How is it dealing with it? Is this going to change the kinds of narrative structures available for the representation of culture? Is it, to the extent that it continues, going to change the dynamics of the Other? 
Whether globalization means homogenization is another question, and we can talk about that. But I don't think anthropologists by a long shot have bought into the homogenization worry. The trouble is that you can't, at least not very easily, do away with the culture concept as we've known it, particularly in terms of setting up an object of study for ethnography. You have to go out into the field with the idea that there's a culture there, and therefore there's a community there, and therefore there's a collectivity that can be probed in a particular sort of way. You're in trouble if you do away with that, because so many of the assumptions of ethnographic inquiry are based upon that. One can attempt to deal with diversity in terms of a model of hybridity, or something, but none of these models are actually guides for investigation. At this point, they're conceptual offerings that are really not much help when you actually go out there and try to figure things out.

The culture concept was something that you actually assumed was there when you were doing work in the field ...

\section{This would be a generation ago?}

Yes, and on-[Clifford] Geertz and on. The culture concept was very useful because you do need a basic ordering sense of things when you go out there and talk to people. And if you've undercut that, there is nothing right now with which to replace it. I'm dubious that you can carry out investigations without a basic, underlying conceptual ordering mechanism like culture and do serious ethnography. The problem I see with many of the contemporary ethnographies that are trying to move away from the culture concept is that they are dominated by a theoretical fiat of some sort that imposes immediate order on the object of investigation. The whole point of the critique was not to let that kind of closure happen too quickly because with the term "culture" a similar closure often happened immediately. You knew the parameters of what you were doing. It defined a craft.

So, historically, even though people have been preoccupied with stretching the culture concept, trying to expand it and reformulate it, there's always been a danger of conceptual closure.

Well, closure was willed in traditional social anthropology. That was our craft and you don't have a craft without knowing conceptually what it is you' re doing. But let's say that we're going to experiment with that, that we're not going to let that closure happen. I suppose we've allowed all these other concepts-hybridity, public culture, and all-to come in. And these concepts are stimulating, but the trouble is that they don't change the bottom line, and the bottom line for someone who's training in area studies or anthropology is that if you don't know the language and the cultural order it entails, you really can't do anything seriously. If you haven't gone around and been confused or surprised by people and their idioms, you really, really, as an ethnographer, don't know what you're talking about. Some may call it ethnography because they've gotten close to some real people, but they haven't actually spent the time and experienced the torment. And I guess that's pretty basic. 
The field, then, is still the authenticating space for ethnography?

Yeah, but the nature of the field, as I will talk about in my afternoon lecture "On Multi-Sited Ethnography," has to change.

How?

Otherwise it becomes a very limited practice to do ethnography, limited in the sense of you're doing what anthropologists have always done, you're showing how people have lived elsewhere-not that that's a trivial matter-but with that kind of ethnography you can't engage in any of the debates of Cultural Studies. You can only engage - boringly, I think - in timeless debates about essentialist questions: does "man" do this, does "man" do that—and then you say, "Among the Semai they don't do war," or something like that. Well, just based upon the critiques of epistemology and representation, none of these questions can even be properly asked, even though they continue to be naively asked. So you have to be ethnographic about the very direction and uses of ethnography itself. That's the reason why yesterday I was taking ethnography totally out of its traditional realm and trying to apply it as the model for doing what is actually a certain kind of intellectual history.

An ethnography of philosophy perhaps?

Right, but as a means of cultural critique, not just to leave it there, but to try to create a means to explore something you never expected you could explore with culture. To me that's exciting: to create a new identity for ethnography. 